\title{
Throat colonization of neonatal nursery staff by Ureaplasma urealyticum: An infection control or occupational health consideration?
}

\author{
Joanne E EMbree md frcpc, Michelle Alfa phd, Joy Lertzman rn, Gloria Gray rt, \\ CARLOS FAJARDO MD, ANNALEE YASSI MD FRCPC
}

\begin{abstract}
JE Embree, M Alfa, J Lertzman, G Gray, C Fajardo, A Yassi. Throat colonization of neonatal nursery staff by Ureaplasma urealyticum: An infection control or occupational health consideration? Can $\mathrm{J}$ Infect Dis 1994;5(5):233-236. Very low birth weight infants often have protracted respiratory tract colonization with Ureaplasma urealyticum. To determine whether prolonged contact with very low birth weight infants resulted in higher rates of upper respiratory tract colonization with this organism for caregivers, throat swabs for U urealyticum culture were obtained from medical, nursing and other support staff working in the neonatal intensive care and level II nurseries at the Health Sciences Centre and the St Boniface Hospital in Winnipeg, Manitoba. Throat colonization by U urealyticum was demonstrated in $7.3 \%$ (95\% Cl 0 to $15.6 \%$ ) of 41 nurses working in the intensive care nurseries but in none of the 48 nurses working in other locations or the 66 other individuals tested $(\mathrm{P}=0.02)$. However, throat colonization was not significantly higher among the neonatal intensive care nurses than among the women delivering at one of the study institutions. Close contact with very low birth weight infants appears to constitute a minimal risk for increased throat colonization with U urealyticum among hospital staff members.
\end{abstract}

Key Words: Infection control, Occupational health. Throat colonization, Ureaplasma urealyticum

\section{Colonisation par Ureaplasma urealyticum de la gorge chez le personnel d'une pouponnière : Le problème relève-t-il de la lutte contre l'infection ou de la sécurité du travail?}

RÉSUMÉ : Les enfants de très petit poids à la naissance souffrent souvent d'une colonisation de leurs voies respiratoires par Ureaplasma urealyticum. Pour déterminer si le contact prolongé avec des enfants de petit poids à la naissance a donné lieu à des taux plus élevés de colonisation des voies respiratoires supérieures chez le personnel soignant, des prélèvements de gorge pour cultures afin de déceler la présence de U urealyticum, ont été obtenus auprès du personnel médical, infirmier et autre, d'unités de soins intensifs néonataux et de pouponnières de niveau II au Health Sciences Centre et au St.Boniface Hospital de Winnipeg au Manitoba. Une colonisation de la gorge par U urealyticum a été observée chez 7,3\% (intervalle de confiance de $95 \%$, de 0 à 15,6\%) des 41 infirmières des pouponnières de soins intensifs, mais n’a été notée chez aucune des 48 infirmières qui travaillaient en d'autres endroits, ni chez 66 autres sujets soumis à cet examen $(\mathrm{P}=0,02)$. Toutefois, la colonisation de la gorge n'a pas été nettement plus élevée parmi les infirmières de soins intensifs néonataux que parmi les accouchées de l'un de ces deux établissements. La proximité des nourrissons de petit poids à la naissance semble représenter un risque minime de colonisation accrue de la gorge par U urealyticum auprès du personnel hospitalier. 
$\mathrm{I}$ NTEREST HAS RECENTLY BEEN DIRECTED TOWARDS THE potential pathogenic role that Ureaplasma urealyticum may play in the development of acute and chronic lung disease in very low birth weight infants. The organism can readily be recovered from various sites in the infant's respiratory tract as well as from the genital tract of female infants. Both term and preterm infants may become colonized with $U$ urealyticum following delivery, with isolation rates varying from 0 to $53 \%$ (1-9). However, colonization is reported more frequently among preterm infants and is often persistent. lasting for several months following birth. Persistent respiratory tract colonization among preterm infants has been associated with the development of bronchopulmonary dysplasia (10-13). Although there are no treatment trials, anecdotal reports show that the organism may still be recovered following therapy with erythromycin, implying either that this drug does not reliably eradicate it or that there is subsequent nosocomial transmission from other infants or from colonized caregivers (14). Throat colonization of adults by $U$ urealyticum has been reported to occur rarely but the actual prevalence of $U$ urealyticum in the upper respiratory tract of adults is unknown (1). Recently, we documented $U$ urealyticum throat colonization in 1.8 and $3.8 \%$ of mothers delivering term and preterm infants, respectively, at one of our hospitals (unpublished data). Hence, we questioned whether throat colonization by $U$ urealyticum of adults involved in the care of these infants might be a potential source of infant infection or reinfection in the neonatal nursery.

As infants with bronchopulmonary dysplasia tend to have very prolonged hospital stays, the prevalence of $U$ urealyticum in neonatal nurseries with a high percentage of low birth weight infants may be significant. If staff caring for these infants readily become colonized from contact with $U$ urealyticum from the infant's respiratory secretions, then continuous exposure to infected infants in the neonatal intensive care setting would be expected to result in an increased upper respiratory tract colonization rate among the hospital staff with close contact with these infants compared with other staff and the general population. To determine whether there was an increased rate of upper respiratory tract colonization by U urealyticum among neonatal intensive care unit staff, we conducted the following cross-sectional study at the two hospitals in Winnipeg, Manitoba that provide acute and chronic care for very low birth weight infants.

\section{PATIENTS AND METHODS}

Following informed consent, throat swab cultures were performed on various personnel working in the neonatal tertiary and secondary level intensive care units at both the Health Sciences Centre (HSC) and St Boniface Hospital (StB) during March 1993.

Samples were obtained using throat swabs for con-
TABLE 1

Ureaplasma urealyticum isolation from staff members in neonatal intensive care units

\begin{tabular}{llcc}
\hline Nursing unit & Occupation & $\begin{array}{c}\text { Number } \\
\text { tested }\end{array}$ & $\begin{array}{c}\text { U urealyticum } \\
\text { isolation }\end{array}$ \\
\hline StB - NICU & Doctor & 5 & 0 \\
& Nurse & 12 & $1(8.3 \%)$ \\
HSC - NICU & Other & 8 & 0 \\
& Doctor & 6 & 0 \\
StB - L2 & Nurse & 29 & $2(6.9 \%)$ \\
& Other & 20 & 0 \\
& Doctor & 3 & 0 \\
HSC - L2 & Nurse & 21 & 0 \\
& Other & 1 & 0 \\
& Doctor & 12 & 0 \\
& Nurse & 27 & 0 \\
\hline
\end{tabular}

HSC Health Sciences Centre; L2 Level 2 nursery: NICU Neonatal intensive care unit: StB St Boniface Hospital

venience and because of the previous report of throat colonization by U urealyticum (1). However, the sites of upper respiratory tract colonization in adults have not been studied and another method of sampling, such as nasopharyngeal swabs, might have yielded a higher colonization rate. The issue of hand carriage was also not addressed in this study because the assumption was made that such carriage would be related to upper respiratory tract colonization.

All nursing, medical and support staff were invited to participate. The testing was anonymous with only the profession and the unit in which he or she was working when recruited recorded for each individual.

Calgiswabs (Spectrum Laboratories, Illinois) were used to collect the throat cultures. They were placed directly into bromothymol blue broth (B broth) (15) and transported directly to the microbiology research laboratories at $\mathrm{StB}$ and $\mathrm{HSC}$ hospitals. The $\mathrm{B}$ broth was incubated aerobically at $37^{\circ} \mathrm{C}$ and inspected daily for any colour change from yellow to green (an indication of growth of mycoplasmas). B broth tubes were held for a total of five days. Once a colour change was detected, the broth was subcultured onto GM agar (15) to observe colonial morphology. If no colour change was detected, the $\mathrm{B}$ broth was subcultured on day 3 to check for ureaplasmal growth that might have gone unnoticed due to competing $\mathrm{pH}$ changes. GM agar plates were incubated for $48 \mathrm{~h}$ at $37^{\circ} \mathrm{C}$ in a carbon dioxide incubator. When colonies were detected a urease spot test was used to detect $U$ urealyticum.

Colonization rates were compared using the twotailed Fisher exact test.

\section{RESULTS}

In total, 155 individuals agreed to be tested. Only nine who were asked to take part refused. Nurses involved in direct patient care formed the largest group 
tested. The doctors tested included neonatologists, neonatal fellows and pediatric residents (11) as well as consulting pediatricians who happened to attend patients in the unit during the time the study was conducted (nine). The other personnel involved included two respiratory technologists, ward clerks, clinical laboratory technologists, pharmacy personnel, occupational therapists, nurses' aids and cleaning staff. The colonization rate, the number tested in each unit and the number in each professional group are shown in Table 1. U urealyticum was isolated from only three individuals $(2 \%)$. All colonized staff were nurses involved in direct patient care while working in the neonatal intensive care units; thus, the rate of colonization in that group was $7.3 \%(95 \% \mathrm{CI} 0$ to $15.6 \%)$ while that in all other groups was $0(\mathrm{P}=0.02)$. In this study other demographic data were not collected; however, approximately $90 \%$ of the nurses and $50 \%$ of the other staff tested were women of reproductive age.

\section{DISCUSSION}

$U$ urealyticum was isolated from throat swabs from $2 \%$ of all staff and from $7.3 \%$ of nurses working in the neonatal intensive care units of the two hospitals surveyed. The isolation rate in nurses working in the intensive care units was significantly higher than that of other nurses and staff. However, it was not significantly higher $(\mathrm{P}=0.1)$ compared with the rates of throat colonization among women delivering at one of the study hospitals in a survey conducted during the previous year and completed six months before this study. In that study, $U$ urealyticum was cultured from throat swabs in $1.8 \%$ of 108 mothers delivering at term and $3.8 \%$ of 104 women delivering prematurely (unpublished data). While these results may not be strictly comparable because the studies were conducted during separate time periods, the population served by the hospital in which the preceding study was conducted is stable, and thus the patient colonization rates were unlikely to vary appreciably over the short time period that elapsed between the two studies.

There may be workplace exposure to $U$ urealyticum through the intensive care of very low birth weight infants, as implied by the higher rate of isolation from throat swabs among the nurses in the intensive care units compared with that of nurses working in other units and of the other groups tested. The nurses in the tertiary care areas had close contact with ventilated premature infants, and in the course of their duties had frequent exposure to the respiratory secretions of these infants. In contrast, nurses in the secondary level nurseries did not care for ventilated patients and generally had much less contact with respiratory secretions. The other staff had variable close contact with the patients, and with the exception of the attending neonatologists, neonatal fellows, pediatric residents and respiratory therapists, had no contact with respiratory secretions.
However, this exposure to secretions does not appear to place the nurses in the neonatal intensive care setting at our institutions at a significantly increased risk for respiratory tract acquisition of the organism compared with women who delivered their infants at one of the study institutions. Carriage of $U$ urealyticum by the nurses may be related to independent factors related to being primarily women of child-bearing age. Despite the $90 \%$ predominance of premature infants in the neonatal intensive care units evaluated in this study, our previous study completed six months earlier revealed that only $9.6 \%$ of 115 premature infants admitted to one of the units were colonized with U urealyticum. This low prevalence of $U$ urealyticum among infants in one of our institutions may explain why we did not observe a high rate of throat colonization among caregivers. Of note, the rates of genital isolation of $U$ urealyticum among our pregnant population is approximately $20 \%$, which is lower than most reports in the literature in which rates vary from 30 to $80 \%(1-3,5)$. In our institutions, respiratory tract carriage of $U$ urealyticum by nursing and medical staff is unlikely to increase substantially the risk of infection by this organism for infants in our nurseries above that of perinatal transmission. However, this may be reflective of the relatively low prevalence of the organsims in our population, and surveys in other centres with higher $U$ urealyticum prevalence may yield different results. To our knowledge, this is the only published study addressing the issue of $U$ urealyticum respiratory tract colonization by medical staff who provide care for neonates.

Determination of whether nosocomial transmission occurs from adults who have upper respiratory tract carriage of $U$ urealyticum to premature infants would be important before the institution of screening and treatment regimens designed to prevent or modify bronchopulmonary dysplasia among infants with perinatally acquired $U$ urealyticum infection.

\section{REFERENCES}

1. Cassell GH, Cole BC. Mycoplasmas as agents of human diseases. N Engl J Med 1981:304:80-9.

2. Sanchez PJ, Regan JA. Vertical transmission of Ureaplasma urealyticum in full term infants. Pediatr Infect Dis J 1987:6:825-6.

3. Syrogiannopoulos GA, Kapatais-Zoumbos K, Decavales GO, et al. Ureaplasma urealyticum colonization of full term infants: perinatal acquisition and persistence during early infancy. Pediatr Infect Dis J 1990;9:236-40.

4. Klein JO, Buckland D, Finland M. Colonization of newborn infants by mycoplasmas. N Engl J Med 1969:280:1025-30.

5. Sanchez PJ, Regan JA. Vertical transmission of Ureaplasma urealyticum from mothers to preterm infants. Pediatr Infect Dis J 1990:9:398-401.

6. Dinsmoor MJ, Ramamurthy RS, Gibbs RS. Transmission of genital mycoplasmas from mother to neonate in women with prolonged membrane rupture. Pediatr Infect Dis J 1989:8:483-7.

7. Foy HM, Kenny GE, Levinsohn EM. et al. Acquisition of 
mycoplasmata and T-strains during infancy. $J$ Infect Dis 1970;121:579-87.

8. Rudd PT, Carrington D. A prospective study of chlamydial, mycoplasmal, and viral infections in a neonatal intensive care unit. Arch Dis Child 1984;59:120-5.

9. Sanchez PJ, Regan JA. Ureaplasma urealyticum colonization and chronic lung disease in low birth weight infants. Pediatr Infect Dis J 1988;7:542-6.

10. Wang EL, Frayha H, Watts J, et al. Role of Ureaplasma urealyticum and other pathogens in the development of chronic lung disease of prematurity. Pediatr Infect Dis J 1988:7:547-51.

11. Cassell GH, Waites KB. Crouse DT, et al. Association of Ureaplasma urealyticum infection of the lower respiratory tract with chronic lung disease and death in very-low-birth-weight infants. Lancet 1988;ii:240-4.

12. Horowitz S, Landau D, Shinwell ES, et al. Respiratory tract colonization with Ureaplasma urealyticum and bronchopulmonary dysplasia in neonates in southern Israel. Pediatr Infect Dis J 1992;1 1:847-51.

13. Walsh WF, Stanley S, Lally KP, et al. Ureaplasma urealyticum demonstrated by open lung biopsy in newborns with chronic lung disease. Pediatr Infect Dis J 1991;10:823-7.

14. Waites KB, Crouse DT, Cassell GH. Antibiotic susceptibilities and therapeutic options for Ureaplasma urealyticum infections in neonates. Pediatr Infect Dis J 1992:1 1:23-9.

15. Robertson JA. Bromothymol blue broth: improved medium for detection of Ureaplasma urealyticum (T-strain mycoplasma). J Clin Microbiol 1978:7:127-32. 


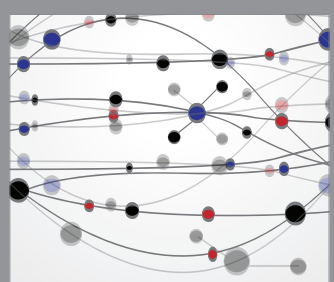

The Scientific World Journal
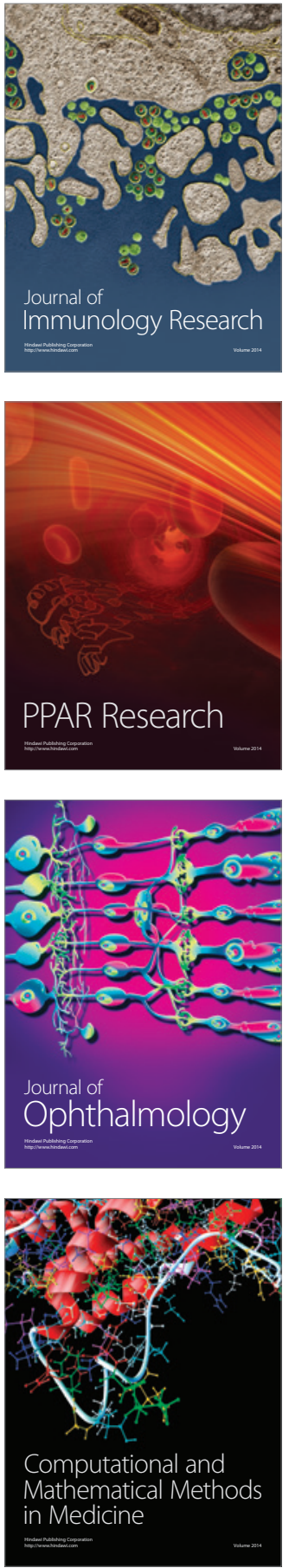

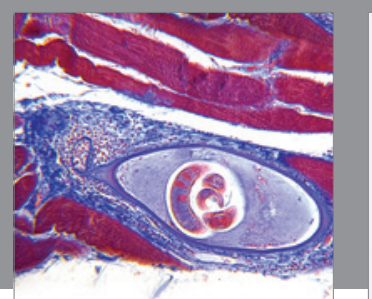

Gastroenterology Research and Practice

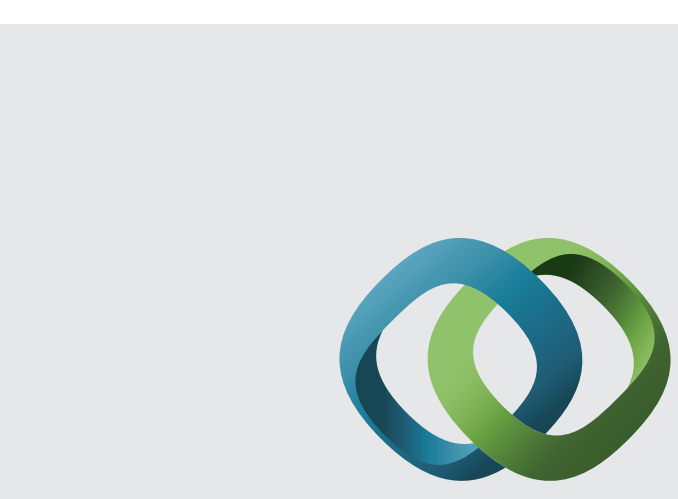

\section{Hindawi}

Submit your manuscripts at

http://www.hindawi.com
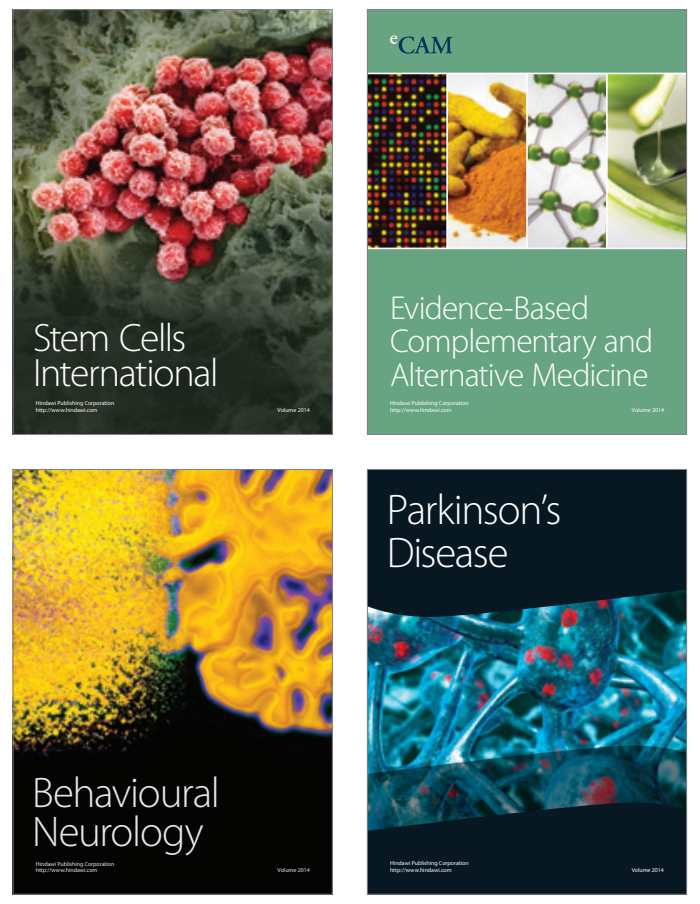
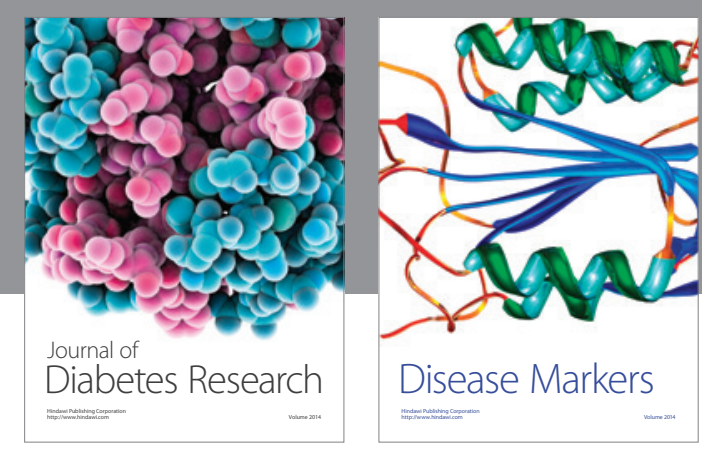

Disease Markers
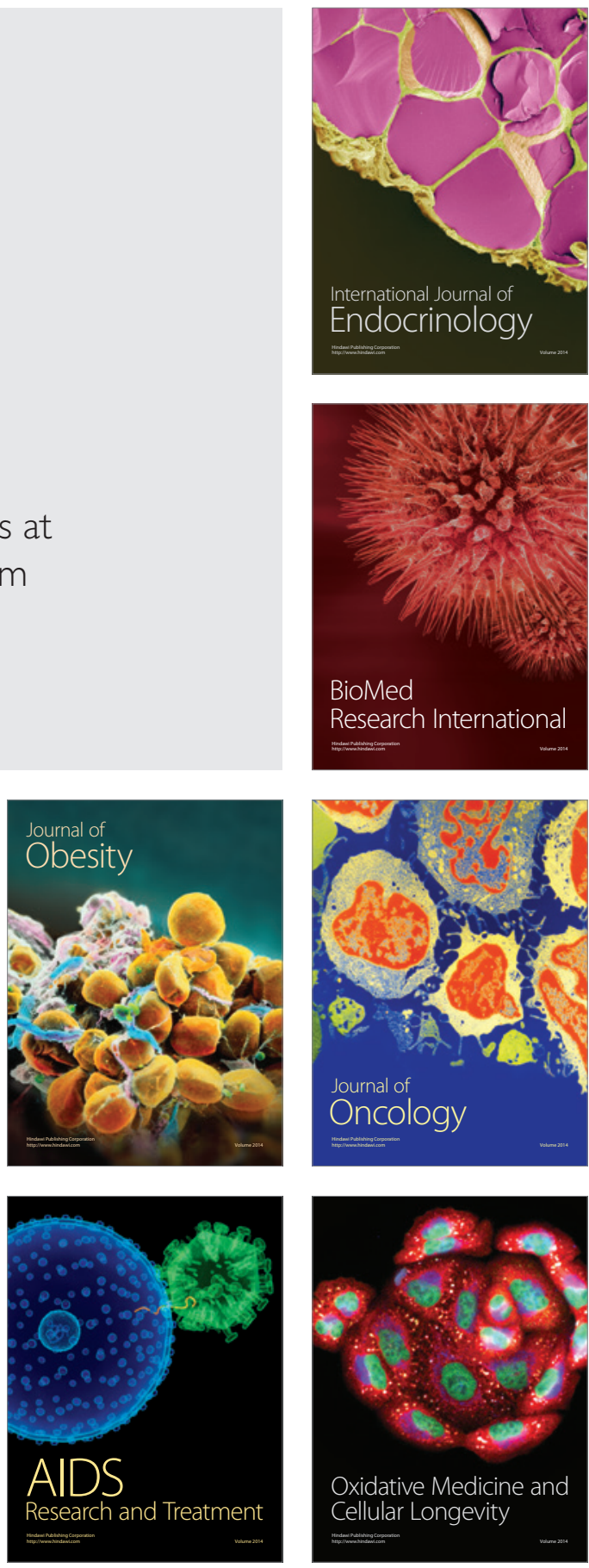